\title{
Aerobic and anaerobic iron oxidizers together drive denitrification and carbon cycling at marine iron-rich hydrothermal vents
}

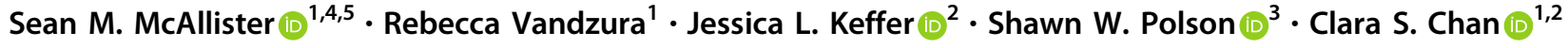

Received: 14 June 2020 / Revised: 6 November 2020 / Accepted: 18 November 2020 / Published online: 17 December 2020

(c) The Author(s) 2020. This article is published with open access

\begin{abstract}
In principle, iron oxidation can fuel significant primary productivity and nutrient cycling in dark environments such as the deep sea. However, we have an extremely limited understanding of the ecology of iron-based ecosystems, and thus the linkages between iron oxidation, carbon cycling, and nitrate reduction. Here we investigate iron microbial mats from hydrothermal vents at Lō'ihi Seamount, Hawai'i, using genome-resolved metagenomics and metatranscriptomics to reconstruct potential microbial roles and interactions. Our results show that the aerobic iron-oxidizing Zetaproteobacteria are the primary producers, concentrated at the oxic mat surface. Their fixed carbon supports heterotrophs deeper in the mat, notably the second most abundant organism, Candidatus Ferristratum sp. (uncultivated gen. nov.) from the uncharacterized DTB120 phylum. Candidatus Ferristratum sp., described using nine high-quality metagenome-assembled genomes with similar distributions of genes, expressed nitrate reduction genes $n a r G H$ and the iron oxidation gene $c y c 2$ in situ and in response to $\mathrm{Fe}(\mathrm{II})$ in a shipboard incubation, suggesting it is an anaerobic nitrate-reducing iron oxidizer. Candidatus Ferristratum sp. lacks a full denitrification pathway, relying on Zetaproteobacteria to remove intermediates like nitrite. Thus, at Lō'ihi, anaerobic iron oxidizers coexist with and are dependent on aerobic iron oxidizers. In total, our work shows how key community members work together to connect iron oxidation with carbon and nitrogen cycling, thus driving the biogeochemistry of exported fluids.
\end{abstract}

Supplementary information The online version of this article (https:// doi.org/10.1038/s41396-020-00849-y) contains supplementary material, which is available to authorized users.

$\triangle$ Clara S. Chan

cschan@udel.edu

1 School of Marine Science and Policy, University of Delaware, Newark, DE, USA

2 Department of Earth Sciences, University of Delaware, Newark, DE, USA

3 Center for Bioinformatics and Computational Biology, University of Delaware, Newark, DE, USA

4 Present address: The Cooperative Institute for Climate, Ocean, and Ecosystem Studies, University of Washington, Seattle, WA, USA

5 Present address: Pacific Marine Environmental Laboratory, National Oceanic and Atmospheric Administration, Seattle, WA, USA

\section{Introduction}

Chemolithotrophy fuels primary production and nutrient cycling in dark environments (e.g., [1-3]). This has been well demonstrated for deep sea sulfur-oxidizing ecosystems (e.g., [4, 5]), yet at the bottom of the ocean, the most abundant source of energy for chemolithotrophy is iron that originates from basaltic ocean crust [6]. Iron-oxidizing microbial communities can be found associated with widespread hydrothermal vents at the ocean floor (i.e., [7-17]). The best-studied example is Lō'ihi Seamount (also in publication as Loihi Seamount), a submarine volcano near Hawai' $i$ with extensive iron microbial mats associated with low- to mid-temperature vents [11, 14, 18-20]. These distinctive biomineral mats at Lō'ihi are produced by the Zetaproteobacteria [21, 22], a class of aerobic autotrophic iron oxidizers that are the only known iron oxidizers in the mat. While the Zetaproteobacteria are relatively wellstudied [7, 23, 24], the ecology of their microbial mats is poorly explored. Metabolic predictions are largely based on isolate physiology studies [25, 26] and genomic potential $[19,20,24]$ of the Zetaproteobacteria, while the functions of 
other, flanking members of the microbial community have largely been inferred from 16S rRNA gene taxonomy, which assumes metabolism is tied with taxonomic affiliation $[8,11,18]$. However, this approach overlooks the roles of uncharacterized taxa such as the DTB120 phylum, found at Lō'ihi $[11,20]$, as well as viral communities that may moderate mat ecology and mediate nutrient fluxes [27]. Thus, major questions remain about the metabolisms and biogeochemical roles of these iron oxidation-driven ecosystems.

One key question is how iron oxidation drives carbon cycling throughout the iron mat. Lō'ihi mats are somewhat enriched in ${ }^{13} \mathrm{C}$ [28], consistent with primary productivity. A study using quantitative PCR showed that the CalvinBenson-Bassham (CBB) pathway gene $c b b M / r b c L$ is much more abundant than $a c l B$ (reductive tricarboxylic acid pathway), suggesting that the CBB pathway is the dominant carbon fixation pathway in the mats [29]. However, not all carbon fixation pathways were investigated and the responsible organisms were not identified. Zetaproteobacteria are often abundant in the mats (ranging from 1 to 96\%) [19, 24], and all have CBB pathway genes, based on isolate and environmental genomes [19, 20, 24-26, 30-33]. Thus, due to abundance and genetic potential, Zetaproteobacteria are the presumed primary producers in the Lo ${ }^{\prime}$ ihi iron mats, yet this has not been definitively shown. Particularly since Zetaproteobacteria are aerobic and oxygen is typically depleted within the first few mm's to cm's of the mat surface [21, 34], there are large anoxic portions of the iron mat where we do not know the source of fixed carbon or the trophic structure of the community. To understand how carbon flow structures the ecosystem, we need to determine how both aerobic and anaerobic organisms contribute to carbon cycling.

Compared to carbon, we know even less about nitrogen cycling in iron-rich mats and vents. The main nitrogen sources at Lō'ihi are vent fluids containing ammonia $(0.28-7.5 \mu \mathrm{M})$ and the surrounding ocean water containing nitrate (36-43 $\mu \mathrm{M})$ [35-37]. Sylvan et al. [35] showed that Lō'ihi vent fluids have elevated nitrate $\mathrm{N}$ and $\mathrm{O}$ isotope ratios, with patterns that suggest denitrification combined with nitrification and/or ammonia oxidation. Some Zetaproteobacteria have genes for nitrate assimilation (nasA) and denitrification (napA/nirK/nirS) [7, 19, 29], but it is unclear if Zetaproteobacteria are the primary drivers of denitrification in the mats. Denitrification within the anaerobic portions of the mat is expected, though it is unknown whether this denitrification is coupled to the oxidation of organic carbon, $\mathrm{Fe}(\mathrm{II})$, or both. The presence of both nitrate and $\mathrm{Fe}(\mathrm{II})$ at $\mathrm{Lo}{ }^{\prime}$ ihi suggests there is a niche for nitratereducing iron oxidizers. However, there has been much debate about whether denitrifying organisms can enzymatically conserve energy from iron oxidation as opposed to chemodenitrification, in which organotrophic denitrification produces nitrite that oxidizes Fe(II) (see review by Bryce et al. [38]). While nitrate reducers that clearly enzymatically oxidize iron largely elude isolation, a number of studies have demonstrated the relevance of coupled iron oxidation and denitrification in coastal marine environments [39, 40], suggesting that it may also be important in other marine environments. These issues are important to resolve if we are to understand how iron, carbon, and nitrogen cycling are linked in deep sea iron systems.

To reconstruct microbial interactions that connect iron oxidation with nutrient cycling, we conducted a genomeresolved metagenomics and metatranscriptomics study at Lō'ihi Seamount. We aimed to better understand the balance of metabolic processes and contributions of specific organisms throughout the mat, including organisms like viruses that have not otherwise been surveyed in iron mats. We collected a surficial mat sample to represent aerobic processes, as well as two bulk samples, which include deeper, anaerobic portions of the mats. The surface sample and one bulk sample were preserved in situ for metatranscriptome studies. We used the other bulk sample in a shipboard incubation experiment in which we added $\mathrm{Fe}(\mathrm{II})$ and oxygen to stimulate aerobic iron oxidation and monitored the transcriptomic response of the community. Our results reveal a fuller picture of the microbial ecology and geochemical cycling in iron microbial mats, including viral influences on dominant community members, nitrogen cycling by Zetaproteobacteria, and a role for a potential nitrate-reducing ironoxidizing Candidatus Ferristratum sp., from the uncharacterized DTB120 phylum.

\section{Methods}

A complete description of sample collection, the Fe(II) amendment experiment, DNA and RNA extraction and sequencing, metagenomic analysis, and RNA read recruitment are provided in McAllister et al. [24], including detailed supplemental information with sample metadata. Here we briefly summarize these methods for Lō'ihi Seamount and describe additional data analysis for this manuscript.

\section{Sample collection}

Three samples were collected at Lō'ihi Seamount, Hawai'i, in March 2013, using the remotely-operated vehicle (ROV) Jason II on the research vessel Thomas G. Thompson. One sample was collected via syringe sampler $(\sim 10 \mathrm{~mL})$, collecting only the top $\mathrm{cm}$ of iron mat (S1). The other two samples were collected in bulk, with S19 by 
scoop sampler $(\sim 2 \mathrm{~L})$ and S6 by suction sampler $(>5 \mathrm{~L})$. To preserve in situ RNA expression profiles, S1 was collected in a syringe half-filled with $2 \mathrm{X}$ RNALater (Invitrogen, Carlsbad, CA, USA) and S19 was collected in a two-chamber scoop where mat material collected in the first chamber was mixed with $2 \mathrm{X}$ RNALater from the second chamber immediately after sampling. Samples were allowed to settle for a few hours at $4{ }^{\circ} \mathrm{C}$ to concentrate the mat before being frozen at $-80^{\circ} \mathrm{C}$.

\section{$\mathrm{Fe}(\mathrm{II})$ amendment experiment}

A shipboard $\mathrm{Fe}(\mathrm{II})$ amendment experiment was performed on the bulk S6 sample, which included iron mat and entrained seawater. Briefly, mat material collected and retrieved after $2 \mathrm{~h}$ of ROV operations was allowed to settle at $4{ }^{\circ} \mathrm{C}$ for $1 \mathrm{~h}$. Two serum bottles were filled with $250 \mathrm{~mL}$ of iron mat floc, with one bottle treated with 1 $\mathrm{mM}$ sodium azide $5 \mathrm{~min}$ prior to the start of the experiment, for a killed control. For the duration of the experiment, both bottles were mixed thoroughly by hand in a $35^{\circ} \mathrm{C}$ water bath. A sample was taken 2 min prior to $\mathrm{Fe}(\mathrm{II})$ amendment (labeled pre-Fe(II) addition). To initiate the experiment, $100 \mu \mathrm{M} \mathrm{FeCl}_{2}$ was added to both bottles. After this addition, at $10 \mathrm{~min}$ intervals for $40 \mathrm{~min}, 30 \mathrm{~mL}$ of sample was removed and mixed 1:1 with $2 \mathrm{X}$ RNALater. Samples were stored at $4{ }^{\circ} \mathrm{C}$ for a few hours prior to freezing at $-80^{\circ} \mathrm{C}$.

\section{DNA and RNA extraction and sequencing}

DNA was extracted from samples using the FastDNA SPIN kit for soil (MP Biomedicals, Santa Ana, CA, USA). RNA was extracted using the NucleoSpin RNA kit (MachereyNagel, Bethlehem, PA, USA). Both kit protocols were followed with modifications (see [24]). Microbial community composition was estimated using a 16S rRNA gene survey using long-read PacBio sequencing, with taxonomy assigned using SILVAngs [41]. Metagenome (MG) and metatranscriptome (MT) libraries were sequenced at the University of Delaware Sequencing and Genotyping Center on an Illumina HiSeq 2500 [24].

\section{Metagenome and metatranscriptome analysis methods}

Quality-controlled metagenome sequences were assembled using metaSPAdes v3.10 [42] and binned into metagenomeassembled genomes (MAGs) using DAS Tool [43] to select the best non-overlapping bins from MaxBin [44], MetaBAT [45], CONCOCT [46], and BinSanity [47], followed by manual curation in ggkbase (https://ggkbase.berkeley.edu/) and Anvi'o [48]. Of the total 215 MAGs from this study, 49 belonged to the Zetaproteobacteria [24]. Quality-controlled metatranscriptomic reads were recruited to curated MAGs and unbinned contigs using BEDTools [49]. RNA expression estimates were calculated from raw read recruitment numbers by normalizing these numbers for sequencing depth and gene and read length using the transcripts per million (TPM) metric [50]. Sample S6 expression, unless otherwise noted, is represented as an average of the expression over the time series. MG and MT relative abundances were calculated as a percentage of reads mapping to binned contigs and contigs that were identified as viral (see below). Maximum normalized TPM values were calculated by dividing TPM by the maximum TPM value across the S6 time series. Testing differential expression in DESeq [51], based on overall gene expression and the expression of genes by MAGs, failed to detect any significantly differentially expressed genes. This is likely due to a lack of replication from sampling limitations, resulting in low statistical power.

\section{Gene identification}

Curated MAGs were submitted to RAST to be annotated by the SEED database [52] and to GhostKoala to be annotated by the KEGG database [53]. Gene calls from RAST were used for all analysis. Genes of interest were identified primarily through HMM searches via the LithoGenie program (github.com/Arkadiy-Garber/LithoGenie). This program uses validated HMMs to identify genes in the $\mathrm{C}, \mathrm{Fe}, \mathrm{N}, \mathrm{S}, \mathrm{As}$, and $\mathrm{H}$ cycles (Supplementary Table 1) (see supplemental data 14 in [54]), including the three clusters of the putative iron oxidase, $c y c 2$ [55]. The clustering of the $c y c 2$ genes was confirmed by phylogenetic reconstruction and comparison with a reference database [24]. A small subset of genes were identified using NCBI BLASTp [56].

\section{DTB120 Identification}

To classify the unknown DTB120 from Lō ihi, we selected 16S rRNA gene representatives from the Desulfobacterota (closest relative; previously known as the Deltaproteobacteria [57]), Zetaproteobacteria, Gallionellaceae, Aquificae, and Chloroflexi within the SILVA database [58]. A 16S rRNA phylogenetic tree of these reference sequences and all DTB120 sequences was constructed from a SINA alignment [59] using RAxML [60] and visualized with Iroki [61].

To identify DTB120 MAGs, we first identified DTB120 16S rRNA genes within all bins initially classified as Desulfobacterota (closest relatives in Phylosift classifier [62]) using the ssu_finder in CheckM [63]. Only four MAGs possessed partial 16S rRNA genes. From these 


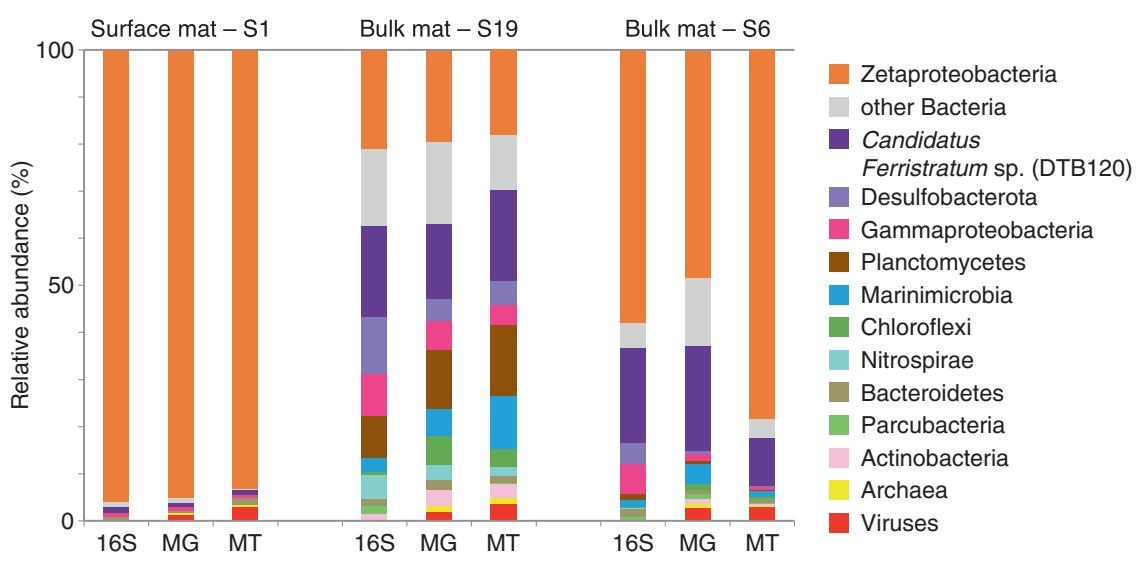

Fig. $1 \mathbf{L o ̄}^{\prime}$ ihi Seamount iron mat microbial community composition based on 16S rRNA gene, metagenome (MG), and metatranscriptome (MT) relative abundance. Zetaproteobacteria and Candidatus Ferristratum sp. were the most abundant taxa. The $16 \mathrm{~S}$
rRNA gene surveyed the bacterial population only. Viral expression based on viral contigs identified from VirSorter. S6 expression shown for pre-Fe(II) addition sample only. reference genomes, we used average amino acid identity (AAI; see supplement) and average nucleotide identity (ANI; data not shown) to identify closely-related MAGs that also belonged to the DTB120 (github.com/mooreryan/ aai). These MAGs were named Candidatus Ferristratum sp.

\section{Viral identification}

Metagenomic contigs representing near-complete phage genomes or containing prophage regions were identified using VirSorter 1.0.3. [64] (lower confidence categories 3 and 6 excluded). Viral contigs were annotated using the VIROME pipeline [65]. Viral taxonomy was determined in two ways: (1) with vContact2 using BLASTp against the ProkViralRefSeq94-Merged database [66] by assigning consensus taxonomy to clusters requiring $100 \%$ reference agreement to assign taxon at a given rank; (2) through consensus taxonomy of Best BLASTp Hit (BBH; $p<1 \mathrm{e}-5)$ for each ORF, with taxon assignment at a rank requiring $\geq 2$ $\mathrm{BBH}$ and $>50 \%$ of all BBHs in agreement [67]. Host-virus interactions were determined using CASC [68]. CRISPR spacers were blasted (BLASTn) against our assembled metagenomes for matches of $>98 \%$ similarity.

\section{Data accessibility}

Raw 16S rRNA gene, metagenome, and metatranscriptome reads were deposited in the NCBI SRA under BioProject accession PRJNA555820. Metagenome assemblies and high-quality MAGs were submitted to the JGI IMG database under sequence project IDs Gp0295814-Gp0295816. All MAGs are available for download from doi:10.6084/ m9.figshare.12986078.v1. Additional sample metadata are available in [24].

\section{Results}

\section{Community composition and activity}

Three samples from Lō'ihi Seamount iron mats were collected: in situ-preserved surface mat S1, in situ-preserved bulk mat S19, and shipboard-preserved bulk mat S6. We evaluated the community structure and activity of the iron mats at Lō'ihi Seamount (Fig. 1) using bacterial 16S rRNA amplicon libraries, metagenome (MG) recruitment, and metatranscriptome (MT) recruitment. We found the abundance estimates provided by all three measurements of microbial community composition were largely consistent with each other, suggesting that the active microbial populations are relatively stable in this iron mat environment.

The most abundant taxonomic group in the Lo 'ihi iron mats was the Zetaproteobacteria, dominating the surface mat sample S1 at $95 \% / 93 \%$ of the community (by MG abundance and MT activity, respectively) (Fig. 1). This high representation of Zetaproteobacteria at the surface of the actively growing mat is expected, due to their role in constructing the iron oxyhydroxide framework of the mat [21]. We were surprised to find the second most active population in the surface mat sample were viruses $(3.1 \%$ by MT abundance). In the bulk mat samples S6 and S19, which include deeper mat, there was a lower abundance of Zetaproteobacteria, accounting for only $48 \% / 19 \%$ of the S6/S19 community by MG abundance and $78 \% / 18 \%$ by MT. Compared to the surface mat $\mathrm{S} 1$, the bulk mat samples were much more diverse, including (in order of decreasing abundance) DTB120, Desulfobacterota, Planctomycetes, Gammaproteobacteria, Marinimicrobia, and Chloroflexi. There was a minor population of Archaea in the bulk mat samples, and viral activity was detected in both bulk samples as well. 


\section{Significant members of the flanking microbial community}

\section{Candidatus Ferristratum}

The second most abundant group in the bulk samples was the DTB120 (0.7\% by MG recruitment in the surface sample S1, $16 \%$ in S19, and $22 \%$ in S6, Fig. 1). DTB120 is an uncharacterized phylum, named for an uncultured clone from a hot spring microbial mat [69], with closest relatives in the Desulfobacterota. Sequences from the DTB120 had a median 16S rRNA sequence identity of $87.6 \%$ (minimum $79.0 \%$ ). The closest cultured relative to our DTB120 sequences is Syntrophorhabdus aromaticivorans, a syntrophic, aromatic compound-degrading microbe isolated from anaerobic digesters [70,71]. Based on a 16S rRNA gene phylogeny of DTB120 (Supplementary Figs. 1 and 2), Syntrophorhabdus spp. are at the base of the DTB120 phylum. However, DTB120 from our samples and other iron-rich hydrothermal vents and seeps (Lō'ihi Seamount, South Tonga Arc, Nile Deep Sea Fan) [11, 16, 20, 72] form a distant and distinct cluster within the DTB120 (minimum 90.1\% identity, Supplementary Fig. 1), leaving the Lō'ihi DTB120 energy metabolism an open question.

Nineteen Lō'ihi DTB120 MAGs clustered into a single genus (62.0-98.6\%, 77.0\% average amino acid identity (AAI); above the $65 \%$ cutoff proposed in [73]) with four of those MAGs positively identified as DTB120 based on partial 16S rRNA genes (Supplementary Fig. 3). Clustering by average nucleotide identity (ANI) yielded an equivalent result (data not shown). Within this DTB120 genus, which we have named Candidatus Ferristratum sp., four subclusters of genomes shared a high enough similarity to form species with more than one genome representative (>95\% AAI; Supplementary Fig. 3B; [73]). However, these species were only represented by a maximum of two MAGs, and were thus not considered to be sufficiently represented to warrant naming at a species level. Of the 19 recovered Candidatus Ferristratum sp. MAGs, 9 are sufficient in quality ( $<20 \%$ redundancy) and completeness ( $>70 \%$ complete) for analyses to predict the metabolic capabilities of the genus (see below; genomes marked with an asterisk in Supplementary Table 2), with the other 10 used for supporting information (Supplementary Table 2). Due to the similarity in their metabolic potential, Candidatus Ferristratum sp. MAGs are largely discussed as a unit.

\section{Viruses}

The iron mats all had substantial viral activity, which has not previously been characterized. To investigate the types of viruses and their potential hosts, we analyzed viral contigs and identified CRISPR spacers within MAGs (Supplementary Table 3). A total of 409 viral contigs (1-82 kb; median $4.7 \mathrm{~kb}$ ) were identified. Based on consensus taxonomic placement, $85 \%$ of contigs were taxonomically associated with the tailed-phage order Caudovirales (Supplementary Fig. 4), with the family Siphoviridae the most numerous in all three samples (Supplementary Table 3). Among other viral groups, three contigs were placed in the ssDNA virus family Inoviridae and several contigs showed similarity to unclassified Halovirus. There were more taxonomically-unassigned contigs within the bulk samples (S19, S6) than in the surface (S1), which indicates an increased novelty of phage in the deeper mat layers.

Aside from several viral contigs that showed consistent Desulfobacterota and Gammaproteobacteria associations, most contigs indicated mixed class- or phylum-level hosts. While not uncommon to see lack of host specificity in a protein homology analysis, the significant variability here is likely indicative of under-characterized phage associations with the dominant microbes, Zetaproteobacteria and Candidatus Ferristratum sp. Host-association was also evidenced within MAGs, as many possessed CRISPR spacer arrays, including the Zetaproteobacteria and Candidatus Ferristratum sp. (Supplementary Table 4). We were able to match two CRISPR spacer sequences from Zetaproteobacteria MAG S1_Zeta3 with $100 \%$ identity to a 28-kb viral contig from S1 containing the nearly complete genome (43 ORFs) of a lysogenic Mu-like phage carrying a Zetaproteobacteria sulfate transporter. One of the spacers was in the first position, indicating the most recent infection, while the existence of a second spacer demonstrated repeated contact between the Zetaproteobacteria and the phage. Numerous other likely lysogenic phage are evident in the libraries including additional $\mathrm{Mu}-$ like phage, filamentous Inoviridae, and several identified prophage elements within the metagenomes (VirSorter categories 4 and 5 in Supplementary Table 3) consistent with past findings of lysogeny in association with microbial mats and effluent associated with geothermal features and other aquatic environments [74, 75]. Such repetitive contact and development of lysogeny indicate long term viral-host interaction, which may have implications for virally-mediated evolution through selective pressure, lysogenic conversion (alteration of host phenotype), and horizontal gene transfer [76].

\section{Lō'ihi mat community metabolisms}

\section{Carbon fixation}

Zetaproteobacteria are thought to be the primary producers within iron mats, using the Calvin-Benson-Bassham 
Fig. 2 Gene expression for carbon fixation, electron donors and electron acceptors within the iron mat. Heatmaps show the total normalized gene expression (TPM) for a carbon fixation, b electron donors and $\mathbf{c}$ electron acceptors, with $\mathbf{d}$ pie charts showing the relative taxonomic contribution to expression. Genes that lacked expression that were still found within MAGs are indicated with gray boxes. Pathways that were not represented in a given sample remain white. Carbon fixation genes were expressed primarily by the Zetaproteobacteria (CBB), though other organisms were also involved: unbinned Methanoperedens sp. (WL) in S1, unbinned Nitrospirae (rTCA and WL) in S6, and

Gammaproteobacteria

Thiotrichales (CBB) and

Actinobacteria (WL) in S19. In addition to iron oxidation, methane oxidation was another significant source of energy in S1, carried out by the unbinned Archaea Methanoperedens (mcrABG) and by the Gammaproteobacteria (pmoABC).

\begin{tabular}{|c|c|c|c|c|}
\hline \multicolumn{5}{|c|}{ Expression } \\
\hline C Fixation & Protein/Gene & S1 & S19 & S6 \\
\hline CBB & RuBisCO Form II & & & \\
\hline rTCA & ATP Citrate Lyase & & 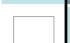 & \\
\hline WL & CO Dehydrogenase & & & \\
\hline
\end{tabular}

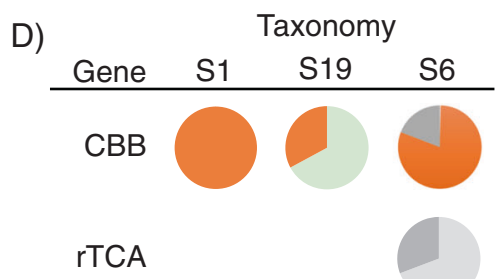

B)

\begin{tabular}{|c|c|c|c|c|}
\hline \multicolumn{5}{|c|}{ Expression } \\
\hline$e^{-}$Donor & Gene & S1 & S19 & S6 \\
\hline $\mathrm{NO}_{2}^{-}$ & $n x r A B$ & & & \\
\hline $\mathrm{NH}_{4}^{+}$ & $h z o A / h z s A$ & & & \\
\hline $\mathrm{Fe}(\mathrm{II})$ & cyc2 & & & \\
\hline $\mathrm{CH}_{4}$ & mcrABG & & & \\
\hline $\mathrm{CH}_{4}$ & $p m o A B C$ & & & \\
\hline$\overline{\mathrm{S}_{2} \mathrm{O}_{3}}$ & $\operatorname{sox} X Z$ & & & \\
\hline $\mathrm{S}_{2} \mathrm{O}_{3}$ & soX $A B C Y$ & & & \\
\hline $\mathrm{S}^{2-} / \mathrm{SO}_{3}{ }^{2-}$ & (rdsr) dsrAB & & & \\
\hline $\mathrm{H}_{2}$ & hya (Group 1) & . & & \\
\hline $\mathrm{H}_{2}$ & hyb (Group 2) & & & \\
\hline $\mathrm{HCOOH}$ & hyf (Group 4) & & & \\
\hline $\mathrm{CO}$ & COXSML & & & \\
\hline
\end{tabular}

C)

\begin{tabular}{|c|c|c|c|c|}
\hline & & Exp & press & \\
\hline $\mathrm{e}^{-}$Acceptor & Gene & S1 & S19 & S6 \\
\hline & cydAB & & & \\
\hline & cyoADE & & & \\
\hline $\mathrm{O}_{2}$ & $\operatorname{COx} A B$ & 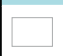 & & \\
\hline & ccoNO & & & \\
\hline $\mathrm{NO}-{ }^{-}$ & narGH & & & \\
\hline $\mathrm{NO}_{3}$ & nap $A B$ & 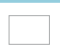 & & \\
\hline $\mathrm{Fe}(\mathrm{III})$ & $m t r A B$ & $\square$ & & \\
\hline $\mathrm{S}_{2} \mathrm{O}_{3}$ & phsA & 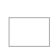 & & \\
\hline
\end{tabular}

$\mathrm{WL}$
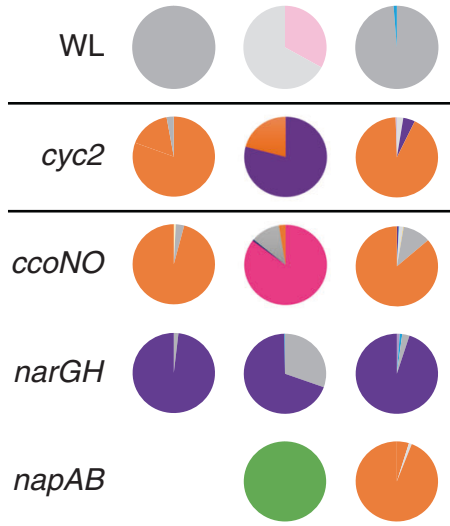

Zetaproteobacteria

Candidatus Ferristratum sp.

Thiotrichales

Chloroflexi

Actinobacteria

Gammaproteobacteria

Marinimicrobia

Other Bacteria

Unbinned

Gene present, but not expressed

Expression (TPM)

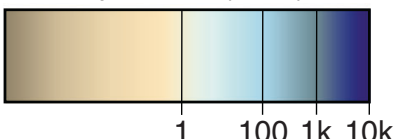

(CBB) cycle [7, 30, 77, 78]. We tested this assumption using HMM profiles from five major carbon fixation pathways (Supplementary Table 1). RuBisCO Form II (catalytic subunit; $r b c L$ ) of the CBB pathway was the highest expressed carbon fixation gene in all three samples, at $53 \times, 17 \times, 5 \times$ higher than the next highest expressed carbon gene for S1, S6, and S19, respectively (Fig. 2a). Surface sample S1 and Fe(II)-amended bulk microcosm S6 had the highest expression levels of RuBisCO Form II, 27-50x higher than in the bulk mat S19, and the majority of those transcripts mapped to Zetaproteobacteria MAGs (Fig. 2d).

\section{Heterotrophy}

Our datasets provide the opportunity to make specific predictions about heterotrophic pathways and organisms. Many MAGs contained genes for degrading polysaccharides such as cellulose and chitin (Supplementary Table 5) [79]. The bulk mat sample S19 contained the greatest number of polysaccharide degradation genes, more than double the number found in surface mat $\mathrm{S} 1$ and microcosm S6. The Candidatus Ferristratum sp. MAGs all lacked autotrophy genes, but several possessed and expressed genes used for polysaccharide degradation. Almost all Candidatus 
Fig. 3 Cyc2 maximum likelihood phylogenetic tree (300 bootstraps) showing the relative placement of $\mathrm{Cyc2}$ belonging to Candidatus Ferristratum sp. MAGs identified in this study. The $c y c 2$ genes found within the Candidatus Ferristratum sp. MAGs form a monophyletic clade (100\% bootstrap support) distinct from the

Zetaproteobacteria.

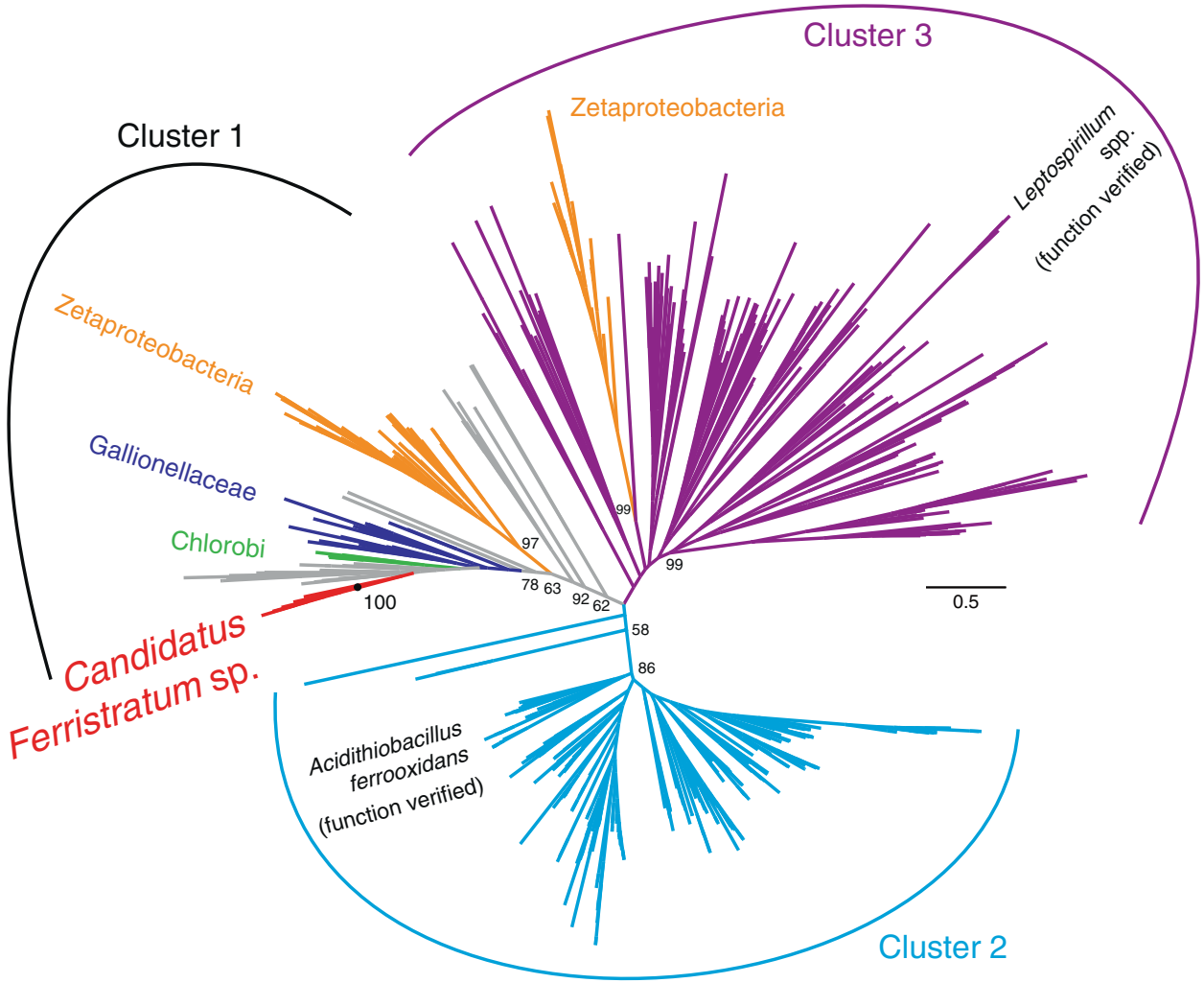

Ferristratum sp. MAGs possessed genes for mannose transport and mannose-6-phosphate isomerase, which channels mannose into glycolysis (Supplementary Table 6). Thus, our analyses uncovered specific evidence for heterotrophy in Candidatus Ferristratum sp. and other flanking community organisms from Lō'ihi iron mats.

\section{Electron donors}

All three Lō'ihi iron mat samples have high expression of $c y c 2$, a potential marker gene for $\mathrm{Fe}$ (II) oxidation (Fig. 2b) [24]. This gene is expressed in all three samples, 2.4-5.3 $\times$ higher than genes for any other energy metabolism (Fig. 2b), making iron oxidation the key metabolism in the iron mats. The $c y c 2$ gene is most highly expressed in the surface mat $\mathrm{S} 1$, which is almost entirely composed of Zetaproteobacteria, and indeed, Zetaproteobacteria account for nearly all the $c y c 2$ expression in $\mathrm{S} 1$ (Fig. 2d). Zetaproteobacteria also dominate $c y c 2$ expression in the Fe(II)-amended bulk microcosm S6, with a small proportion of expression from Candidatus Ferristratum sp. In contrast, the high level of $c y c 2$ expression in the bulk mat S19 can be attributed primarily to Candidatus Ferristratum sp. While the high cyc2 expression by Zetaproteobacteria is consistent with previous work [23, 24], cyc2 expression by Candidatus Ferristratum sp. was an unexpected novel finding, as Zetaproteobacteria were previously the only hydrothermal iron mat organisms known to possess the cyc2 gene. Phylogenetic reconstruction of $\mathrm{Cyc} 2$ sequences from public databases and our samples show that the Candidatus Ferristratum sp. Cyc2 sequences form a monophyletic clade within Cluster 1 (Fig. 3). Their closest neighbors are the Gallionellaceae and Chlorobi, suggesting that the Candidatus Ferristratum sp. did not acquire cyc2 directly from the Zetaproteobacteria. Because Cluster 1 is largely comprised of Cyc2 from established neutrophilic iron-oxidizers, this presents the possibility that the Candidatus Ferristratum sp. may also be an iron oxidizer.

While Fe(II) oxidation appears to be the predominant energy acquisition pathway in all three Lō'ihi mat samples, genes for utilization of a diversity of electron donors are expressed by the non-Zetaproteobacteria flanking community, with notable differences between the surficial and bulk mats (Fig. 2b; taxonomic distribution for all genes in Supplementary Table 7). In the surface mat S1, there is high expression of genes for methane oxidation, consistent with previous reports of methane-oxidizers and methane oxidation genes within iron mats $[72,80,81]$. In contrast to the surface mat, bulk mat S19 and bulk microcosm S6 had higher expression of genes involved in $\mathrm{H}_{2}$ oxidation (Fig. 2b). Oxidative nitrogen transformations were also present but relatively rare in the iron mat genomes and metatranscriptomes (Fig. 2b). 
Fig. 4 Nitrogen cycling gene expression within the iron mat. Heatmap shows the total normalized gene expression (TPM) for different metabolic pathways related to nitrogen cycling (a), with pie charts of relative taxonomic contribution to expression also shown (b). Genes that lacked expression that were still found within MAGs are indicated with gray boxes. Pathways that were not represented in a given sample remain white.

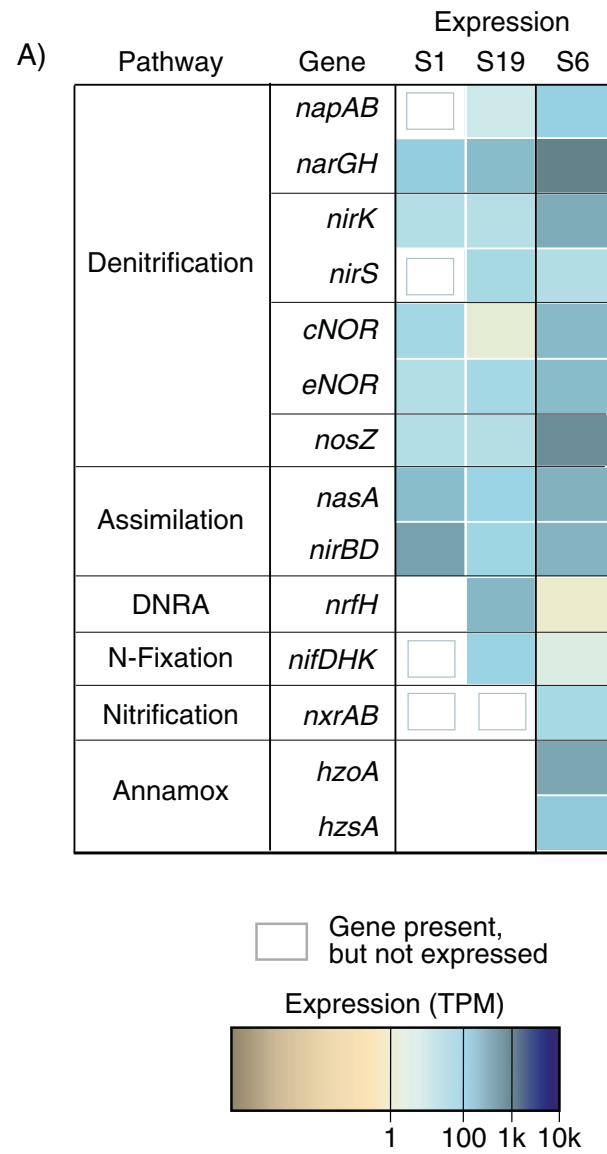

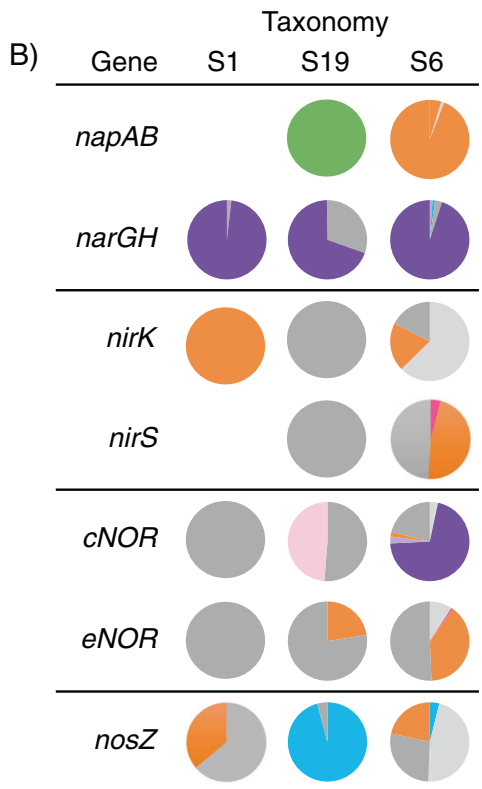

Zetaproteobacteria

Candidatus Ferristratum sp.

Desulfobacterota

Chloroflexi

Actinobacteria

Gammaproteobacteria

Marinimicrobia

Other Bacteria

Unbinned

\section{Electron acceptors}

Genes for oxygen and nitrate respiration were expressed in all Lō'ihi mat samples (Fig. 2c) with differences as expected due to the fact that $\mathrm{S} 1$ sampled the aerobic surface while S19 includes deeper regions of the mat [21, 34]. In the surface sample $\mathrm{S} 1$, the dominant terminal electron acceptor genes were the aerobic $\mathrm{cbb}_{3}$-type $c c o N O, 11.8 \times$ more highly expressed than genes for the next electron acceptor, the respiratory nitrate reductase $n a r G H$, likely reflecting the greater availability of oxygen in the surface mat (Fig. 2c). Bulk mat sample S19 terminal electron acceptor expression was dominated by Candidatus Ferristratum sp. respiratory nitrate reductase $\operatorname{narGH}$ (Fig. 2d), though aerobic terminal oxidases were also expressed, primarily by Gammaproteobacteria. In addition, low levels of expression of nitrate reduction genes $n a p A B$ and iron reduction genes $m \operatorname{tr} A B$ were detected. The bulk microcosm S6 expressed all terminal electron acceptors at the same or a higher level than bulk mat S19.

\section{Nitrogen transformations}

Previous work at Lō'ihi suggested that iron mat microbes actively oxidize and reduce nitrogen species [35]. To better understand the processes and taxa involved, we examined genes involved in nitrogen transformations (Fig. 4). Of these, genes for reductive nitrogen transformations were the highest expressed in all three samples. Genes for full denitrification of nitrate to $\mathrm{N}_{2}$ were expressed in all samples (Fig. 4a), including dissimilatory nitrate reductase (napAB or $n a r G H$ ), nitrite reductase (nirK or nirS), nitric oxide reductase (norBC or eNOR [a family of nitric oxide reductase with a putative proton channel, [82]]), and nitrous oxide reductase (nosZ)), but not all by the same organism (Fig. 4b). Instead, different parts of the pathway were expressed by Candidatus Ferristratum sp., Desulfobacterota, Zetaproteobacteria, Marinimicrobia, Sphingobacteriales, and other unclassified Bacteria.

Nitrogen fixation, nitrification, and anaerobic ammonia oxidation gene expression was detected in the bulk mat S19 
Fig. 5 Gene expression patterns for major taxa during the S6 Fe(II) addition experiment. Maximum normalized gene expression (Max Norm. TPM) totals shown for organisms (a) and genes of interest $(\mathbf{b}, \mathbf{c})$ for the Zetaproteobacteria (left) and Candidatus Ferristratum sp. (right). Genes related to $\mathrm{Fe}$ (II) oxidation (cyc2, ccoNO, narG) (b) are separated from genes involved in denitrification (narG, nirK, eNOR, cNOR, nosZ) (c). Data are shown for the sample pre-Fe(II) addition, as well as at $10 \mathrm{~min}$ intervals starting 2 min after $\mathrm{Fe}$ (II) addition. Organism maximum TPM values: All

Zetaproteobacteria $(621,257)$, all Candidatus Ferristratum sp. $(106,842)$, all viruses $(37,024)$.

Zetaproteobacteria gene maximum TPM values: $c y c 2$ (3,683), ccoNO (826), nirK (787), eNOR (31), nosZ (218). Candidatus Ferristratum sp. gene maximum TPM values: cyc2 (110), narG (1,330), cNOR (106).
A) Total expression per taxa
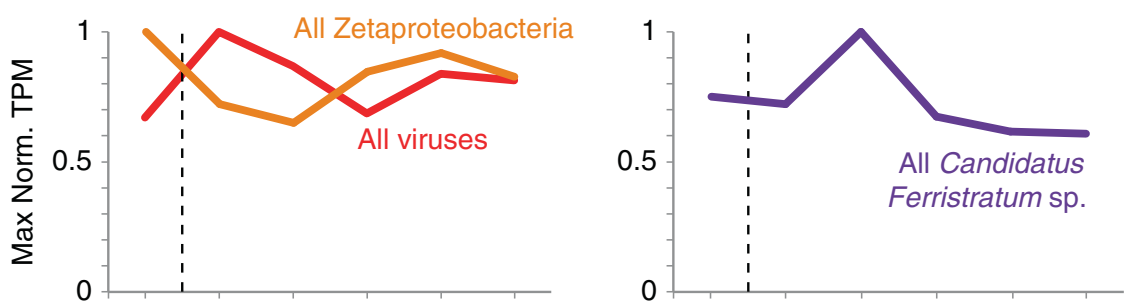

B) Fe-oxidation pathway gene expression
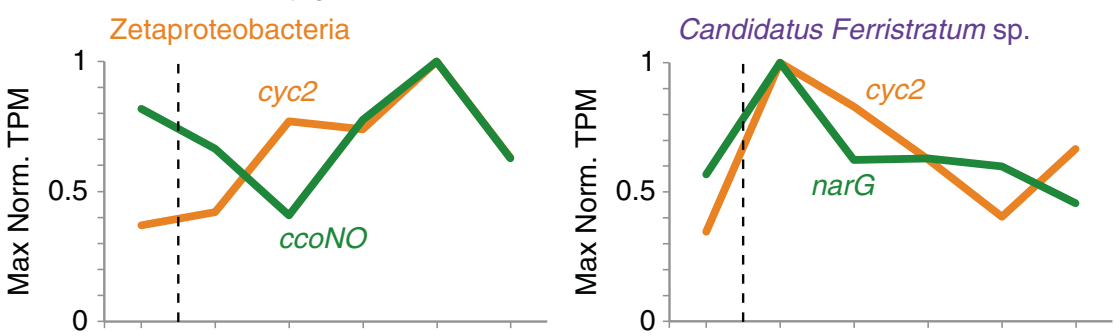

C) Denitrification pathway gene expression
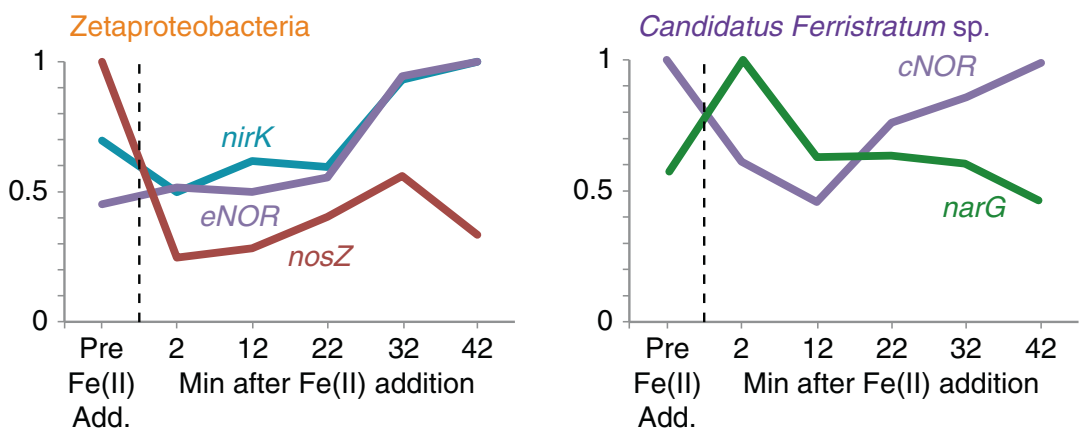

and bulk microcosm S6 at low levels (Fig. 4a). Although nirBD plays a role in dissimilatory nitrate reduction to ammonium (DNRA), the majority of Zetaproteobacteria MAGs possess a gene cluster containing nasA and nirBD together, signaling these genes are likely used in concert for nitrate assimilation [7]. The expression of this assimilatory pathway was highest in S1 and S6, where the Zetaproteobacteria were most abundant. Assimilation of ammonium from environmental sources is mediated by the ammonium transporter encoded by amt, which is found in nearly all Zetaproteobacteria and $75 \%$ of the Candidatus Ferristratum sp. genomes.

\section{Fe(II)-amended bulk microcosm S6 time-series}

To understand how iron oxidation affects community metabolisms, we added Fe(II) to the bulk mat sample S6 under aerobic conditions and then monitored gene expression every $10 \mathrm{~min}$ for $40 \mathrm{~min}$, by which time $\mathrm{Fe}$ (II) was depleted. The S6 microcosm gene expression data showed a wide array of stimulated metabolisms, including both aerobic and anaerobic metabolisms and iron oxidation
(Figs. 2b, c and 4a). In particular, Zetaproteobacteria ccoNO and Candidatus Ferristratum sp. narGH (Fig. 2c, d) were similarly highly expressed, and both taxa were actively expressing $c y c 2$ (Fig. 2c, d).

We evaluated how Zetaproteobacteria and Candidatus Ferristratum sp. transcription responded to $\mathrm{Fe}(\mathrm{II})$ stimulus by examining their individual gene expression patterns over the course of the time series (Fig. 5; we note that shipboard conditions precluded replicates and related statistical analyses). Immediately after $\mathrm{Fe}(\mathrm{II})$ addition, viral activity jumped, while Zetaproteobacteria decreased until $12 \mathrm{~min}$ (T12) before increasing. Candidatus Ferristratum sp. peaked at $12 \mathrm{~min}$, suggesting Candidatus Ferristratum sp. and Zetaproteobacteria activity relate to different conditions (Fig. 5a).

To explore this, we examined genes potentially involved in the aerobic or anaerobic iron oxidation pathway $(c y c 2$, ccoNO, narG) for each taxon (Fig. 5b). In the Zetaproteobacteria, total $c y c 2$ expression continuously increased after $\mathrm{Fe}(\mathrm{II})$ addition until $32 \mathrm{~min}(2.7 \times$ increase), in contrast to expression of the aerobic terminal electron acceptor $(2.5 \times$ increase between lowest and highest values; Fig. 5b, left), 
Fig. 6 Heatmap showing the $\log _{2}$ total normalized gene expression (TPM) for different metabolic pathways related to iron, nitrogen, and oxygen cycling. Expression is shown for representative

Zetaproteobacteria MAGs (left) and near-complete Candidatus Ferristratum sp. MAGs from S6/S19 and the only Candidatus Ferristratum sp. MAG from S1 (right). MAG percent completeness indicated in parentheses. Genes that lacked expression that were still found within MAGs are indicated with gray boxes. Pathways that were not represented in a given MAG remain white.

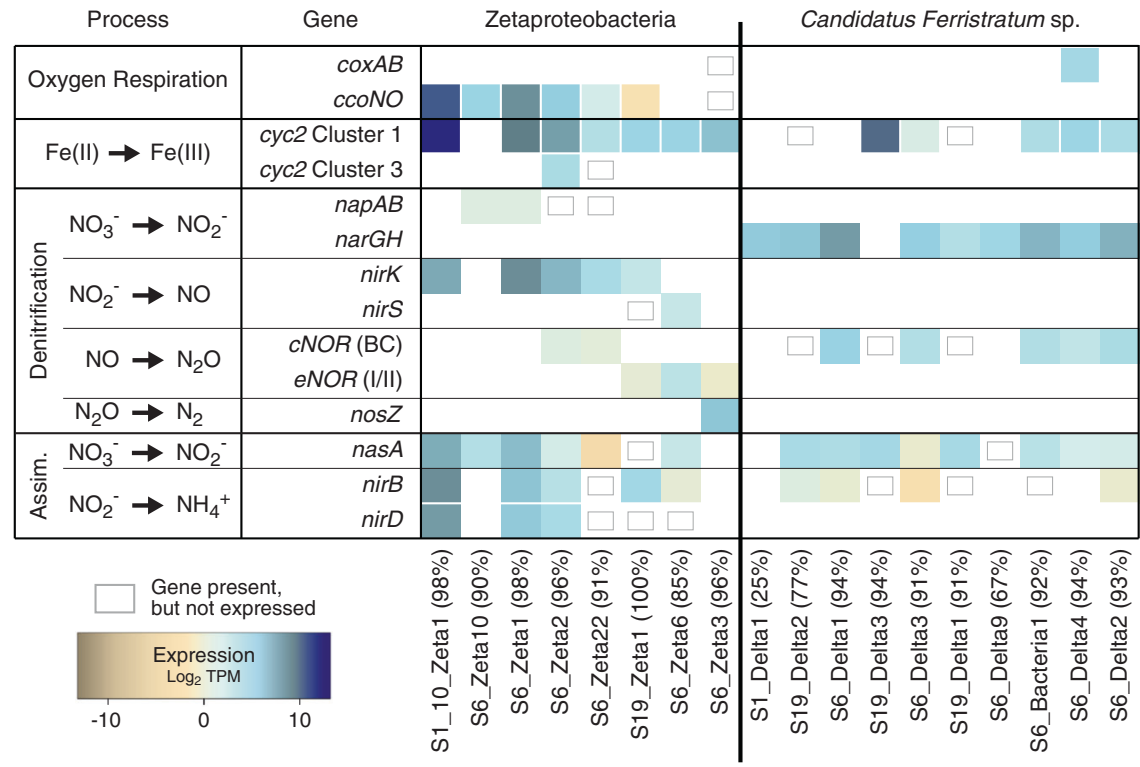

which more closely followed the overall expression pattern of the dominant Zetaproteobacteria (Fig. 5a, left). This suggests that Zetaproteobacteria $c y c 2$ expression is stimulated by $\mathrm{Fe}$ (II) addition [24]. On the other hand, both $c y c 2$ and $\operatorname{narG}$ expression rapidly increased in Candidatus Ferristratum sp. within 2 min after $\mathrm{Fe}(\mathrm{II})$ addition $(2.9 \times$ and $1.8 \times$, respectively), followed by a decline (Fig. 5b, right). The $c y c 2$ and $n a r G$ peak occurred before overall expression in Candidatus Ferristratum sp. peaked, suggesting these genes were specifically upregulated by $\mathrm{Fe}$ (II) addition before other cellular processes were stimulated by iron oxidation (Fig. 5a, b, right).

We also examined gene expression patterns for the denitrification pathway (narG, nirK, eNOR, cNOR, nosZ). With the exception of $\operatorname{nar} G$, the expression pattern shows some similarity between both groups of organisms, in some cases starting high and declining after Fe(II) addition, and then increasing after 2 or $12 \mathrm{~min}$ (Fig. 5c). This suggests that the mat already had sufficient capacity for transforming denitrification intermediates, such as nitrite, and new expression was not immediately necessary. Overall, the trends of Zetaproteobacteria and Candidatus Ferristratum sp. gene expression in response to $\mathrm{Fe}(\mathrm{II})$ addition suggest different niches and biogeochemical roles for these organisms within the gradients of iron mats.

\section{Contribution of individual Zetaproteobacteria and Candidatus Ferristratum sp. MAGs to iron and nitrogen mat cycling}

To better resolve the ecological niches of the major iron mat taxa, we examined the distribution and MAG-specific expression of genes within individual genomes, focusing on near-complete MAGs from the Zetaproteobacteria and
Candidatus Ferristratum sp. (Fig. 6; Candidatus Ferristratum sp. details Supplementary Table 6). The majority of Zetaproteobacteria MAGs expressed both $c y c 2$ and $c \operatorname{coNO}$ at high levels, as expected for aerobic iron-oxidizers (Fig. 6) [24]. Most of these MAGs also expressed the assimilatory nitrate reduction cassette with nasA and nirBD. Most MAGs expressed nirK, but the rest of the dissimilatory denitrification pathway was scattered between individual Zetaproteobacteria MAGs. Notably, several Zetaproteobacteria had the $\operatorname{nap} A B$ nitrate reduction genes, though only two MAGs showed expression at low levels, compared to their aerobic respiratory $c c o N O$ genes.

In contrast, Candidatus Ferristratum sp. metabolic potential was consistent between MAGs. Most of the MAGs possessed $c y c 2$, though individual expression levels varied from undetectable to very high. Only one Candidatus Ferristratum sp. MAG possessed terminal oxidase genes $(\operatorname{cox} A B)$, while the majority instead expressed the narGH nitrate reductase genes (Fig. 6). None of the Candidatus Ferristratum sp. MAGs contained the complete denitrification pathway, only possessing $c N O R$ nitric oxide reduction genes. Although Candidatus Ferristratum sp. appears to be anaerobic, several oxygen detoxification genes were found within the MAGs and were frequently highly expressed (Supplementary Table 6). Additionally, all high-quality Candidatus Ferristratum sp. MAGs possessed the oxygen-independent class II ribonucleotide reductase (RNR), and all but one also possessed the oxygen-sensitive class III RNR. These genes suggest that most Candidatus Ferristratum sp. are adapted to survive aerobic conditions. Given the high expression of $\operatorname{nar} G$, this suggests that the Candidatus Ferristratum sp. are primarily facultative anaerobes that respire nitrate and may be capable of iron oxidation. 
Fig. 7 Cartoon showing the contribution of different members of the microbial community to iron, carbon, and nitrogen cycling within the aerobic/anaerobic gradient of an iron mat. The

Zetaproteobacteria influence nearly every metabolic process in the mat, and support/are supported by a diverse flanking community, including the anaerobic Candidatus Ferristratum sp. The mat community is also supported by other metabolisms, such as oxidation of methane and $\mathrm{H}_{2}$.

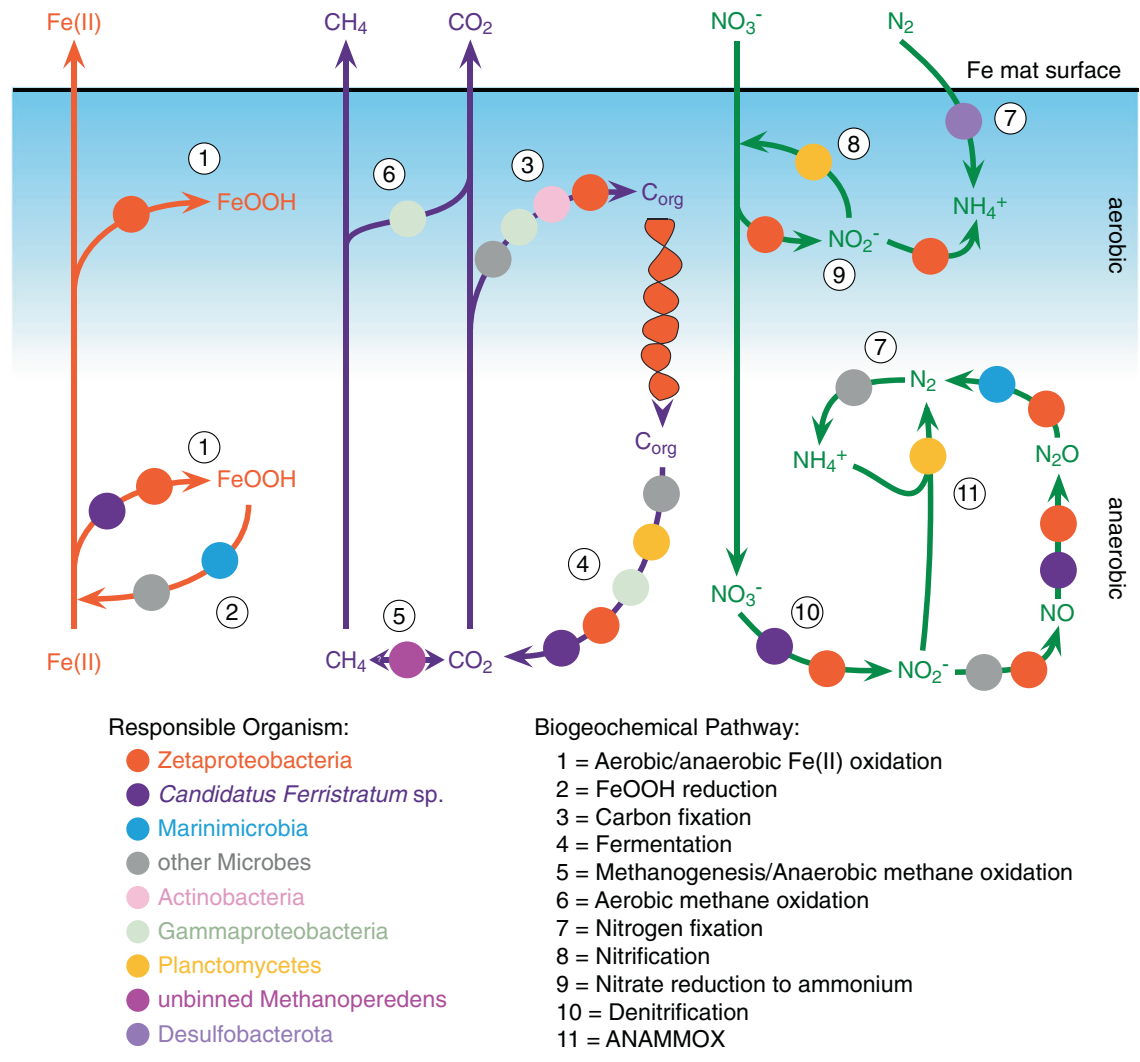

\section{Discussion}

Iron-oxidizing microorganisms can strongly influence the biogeochemical cycles of a wide range of elements. Previous studies have focused primarily on the biomineral byproducts, iron oxyhydroxides, which adsorb and coprecipitate various elements (e.g., [33, 83-86]). However, iron oxidizer physiology and ecological interactions are just as likely to affect biogeochemical cycling. Here, we have explored these interactions within three iron mat samples from Lō'ihi Seamount, comparing community composition and expression in aerobic surface mat (S1) with bulk mat that includes anaerobic niches (S6 and S19). In the S6 bulk mat microcosm, we were able to observe which organisms and processes are most primed to respond to Fe(II). With these samples, we explored the capabilities of individual iron mat members and reconstructed ecological interactions and community impacts on iron, carbon, and nitrogen cycles.

The Lō'ihi Seamount iron mat communities are dominated by a few key players, primarily Bacteria, but also include Archaea and viruses (Figs. 1 and 7). The microbial community is structured by a gradient of oxygen, which becomes undetectable within the first few mm's to cm's of the mat surface [21, 34] Depending on oxygen levels, we find microorganisms involved in either aerobic iron oxidation (Zetaproteobacteria) or anaerobic iron oxidation
(Candidatus Ferristratum sp.). These iron oxidizers (Fig. 7, process 1) form metabolic products ( $\mathrm{Fe}(\mathrm{III}), \mathrm{C}_{\mathrm{org}}, \mathrm{NO}_{2}^{-}$) that support the metabolisms of flanking community microorganisms, thus either directly or indirectly driving most biogeochemical processes in the mat, including iron reduction, carbon fixation, fermentation, nitrate assimilation, and denitrification (Figs. 2 and 7).

Zetaproteobacteria are known to be autotrophs based on culture work and inference from MAGs [19, 20, 25, 77], but a definitive link to primary production in iron mats has not been demonstrated. Our work shows that the Zetaproteobacteria are the primary producers in the surface mat, where nearly all gene expression from known carbon fixation pathways can be attributed to RuBisCO Form II gene expression in the Zetaproteobacteria (Fig. 2). This suggests that carbon fixation is concentrated near the aerobic surface of actively growing mats. This is consistent with microscopy evidence that mats accrete as iron oxidizers form biomineral stalks, positioning the cells at the surface of the mat [21]. The iron oxyhydroxide stalk structures of the Zetaproteobacteria contain polysaccharides [87] and adsorbed organic exudates [88], thus the biominerals act as reservoirs of organic carbon for use by heterotrophs and fermenters. Viral induced lysis is another key mechanism for organic nutrient recycling, such as the viral shunt that maintains a pool of dissolved organic matter driving oceanic carbon cycling in the water column [89]. Given the diversity 
of phage, high abundance of viral transcripts in the metatranscriptomes, and evidence of repeated interaction between viruses and the dominant microbial populations in the mat, it is quite likely that viruses may be playing a similar role mediating carbon bioavailability in the iron mats (Supplementary Tables 3 and 4).

Zetaproteobacteria are aerobes, as no Zetaproteobacteria culture can grow anaerobically [7, 20] and all sequenced Zetaproteobacteria genomes include aerobic terminal oxidase genes [24]. However, some have the genetic potential for using nitrate reduction to live within an aerobic/anaerobic transition zone. A few Zetaproteobacteria genomes from the S6 bulk microcosm have the dissimilatory nitrate reductase genes napAB (Figs. 4 and 6). These organisms may conduct aerobic nitrate reduction, using nitrate as a backup electron acceptor under oxygen limiting conditions [90]. This is consistent with the concurrent expression of genes for terminal oxidase (ccoNO) and nitrate reduction (napAB) (Fig. 6) within the well-mixed S6 microcosm. Furthermore, different Zetaproteobacteria MAGs encode various other parts of the dissimilatory denitrification pathway (Fig. 6). Only the dissimilatory nitrate reductases are known to conserve energy in this pathway, though eNOR may also conserve energy via a proposed proton pump [82]. Thus, Zetaproteobacteria engaging in only part of the pathway may do so as a means of detoxifying intermediates, such as nitric oxide [91], or removing nitrite to avoid abiotic iron oxidation and encrustation in an $\mathrm{Fe}(\mathrm{II})$ rich environment $[38,92]$. Together with evidence of nitrate assimilation (including in $[19,20]$ ), these results show that within the Zetaproteobacteria themselves, iron oxidation and nitrate reduction are coupled in multiple ways.

Since Zetaproteobacteria are primarily aerobes, this leaves anaerobic niches open for other organisms to thrive. Candidatus Ferristratum was overall the second most abundant taxa within the iron mats (Fig. 1) and their high expression of narGH (Figs. 2 and 4) and Cluster 1 Cyc2 homologs (Fig. 3) suggests they are active anaerobic denitrifiers with the ability to oxidize $\mathrm{Fe}(\mathrm{II})$. Given the rapid and parallel responses of $c y c 2$ and narG genes after Fe(II) stimulus (Fig. 5), Candidatus Ferristratum sp. may represent a novel nitrate-reducing iron-oxidizing taxon. Although oxygen was available in the microcosm, the injection of $\mathrm{Fe}(\mathrm{II})$ may have promoted transient anaerobic niches within the mat material. In the environment, Candidatus Ferristratum sp. are much more abundant in bulk mat samples (Fig. 1), including those from previous studies at Lō'ihi Seamount [11, 20]. Our findings suggest there may be two partitioned niches of iron oxidation in iron mats: The Zetaproteobacteria oxidizing iron in the shallow, aerobic zone, and Candidatus Ferristratum sp. conducting nitrate-reducing iron oxidation in the primarily anoxic zone.
The Lō'ihi iron mats should be an ideal place to find nitrate-reducing iron oxidizers, due to gradients of $\mathrm{Fe}(\mathrm{II})$, $\mathrm{O}_{2}$, and $\mathrm{NO}_{3}{ }^{-}$in the mat $[21,34,35]$. Nitrate reduction coupled to iron oxidation is theoretically possible for a single organism, but no isolate aside from the hyperthermophilic Archaea Ferroglobus placidus [93] has been shown to do so unequivocally [38, 94]. Indeed, the model system for nitrate-reducing iron oxidizing bacteria is the $\mathrm{KS}$ enrichment culture containing an autotrophic, nitratereducing iron-oxidizing Gallionellaceae partnered with heterotrophs that complement the Gallionellaceae's denitrification pathway [94-96]. At Lō'ihi, Zetaproteobacteria produce organic carbon and consume oxygen, creating a niche for nitrate-reducing iron oxidizers. However, it is clear that Zetaproteobacteria themselves do not fill this niche, though they can assimilate nitrate using electrons from Fe(II) (Fig. 8, Zetaprotobacteria cell A), and some may conduct aerobic denitrification for redox balance (Zetaproteobacteria cell C). The anaerobic iron oxidation niche is open for another organism, such as the dominant denitrifier Candidatus Ferristratum sp., which may couple nitrate reduction to either iron (Fig. 8, Candidatus Ferristratum cell A) and/or organic carbon oxidation (Candidatus Ferristratum cell B). Either way, the high Candidatus Ferristratum sp. narG expression (Figs. 2 and 4) suggests that significant quantities of nitrite are produced in the mats. In theory, this could rapidly oxidize $\mathrm{Fe}$ (II) through chemodenitrification, which would result in the encrustation of nitrite-producing cells [38, 92]. However, Zetaproteobacteria expressed nirK highly, and increased nirK expression in the Fe(II)-amended bulk microcosm after peak narG expression (Fig. 5), suggesting that the Zetaproteobacteria actively remove nitrite produced by Candidatus Ferristratum sp. (Fig. 8, Zetaproteobacteria cell A). Zetaproteobacteria (cell B; Fig. 8) and Candidatus Ferristratum sp. (cell B) also express genes to reduce $\mathrm{NO}$ via eNOR and $\mathrm{cNOR}$, respectively (Fig. 6), suggesting the need to detoxify NO. Finally, some Zetaproteobacteria can complete denitrification from $\mathrm{N}_{2} \mathrm{O}$ to $\mathrm{N}_{2}$ (cell B; Fig. 8). In this partner approach, a nitrate-reducing iron-oxidizing organism is relieved of the burden of having to synthesize all four separate enzyme complexes to denitrify to $\mathrm{N}_{2}$ because other taxa help with detoxifying byproducts. This cooperative approach to denitrification may explain why it has been challenging to isolate nitrate-reducing iron oxidizers.

\section{Conclusions and implications}

At Lō'ihi Seamount, energy from iron oxidation fuels the growth and ecological interactions of a diverse microbial community. The well-known Zetaproteobacteria colonize 


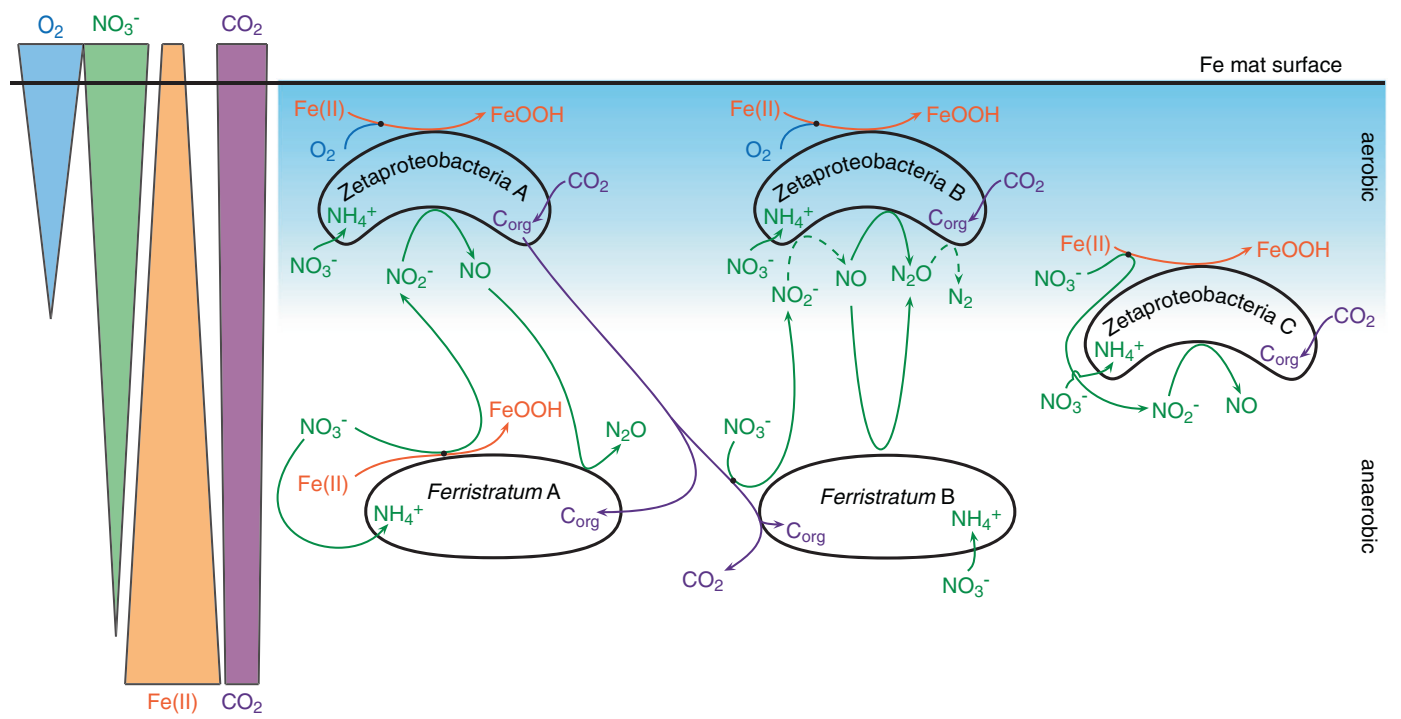

Fig. 8 Cartoon model showing potential $\mathrm{C}$ and $\mathrm{N}$ cycling between the aerobic Zetaproteobacteria and anaerobic Candidatus Ferristratum sp. within the gradient of the iron mat. Letters denote either different Zetaproteobacteria taxa or different potential metabolic strategies in a single Candidatus Ferristratum sp. cell. Zetaproteobacteria A (ZA): Capable of Fe(II) oxidation using oxygen, assimilating nitrate, reducing nitrite, and fixing carbon. ZB: Capable of reducing nitrogen intermediates. All have NOR, though ones with NIR don't have NOS. (see Fig. 6). ZC: A few Zetaproteobacteria with NapA may be able to couple nitrate reduction with iron oxidation (these Zetaproteobacteria also capable of the metabolism in ZA). Candidatus Ferristratum A: Capable of nitrate reduction coupled to iron oxidation. Candidatus Ferristratum B: Capable of nitrate reduction coupled to organic $\mathrm{C}$ oxidation. iron-rich vents [18, 97], oxidize $\mathrm{Fe}(\mathrm{II})$ aerobically, and produce $\mathrm{Fe}$ (III) oxyhydroxide stalks to create the physical framework of the mat [21]. The Zetaproteobacteria use energy and electrons from $\mathrm{Fe}$ (II) to fix carbon, some of which binds to mat biominerals. Organic carbon is also made available through the viral lysis of Zetaproteobacteria, as they are hosts to Mu-like lysogenic phages and in contact with a diverse and active viral assemblage. Zetaproteobacteria oxygen consumption creates anaerobic zones and thus, in these various ways, Zetaproteobacteria create the physical and chemical niche for the nitrate-reducing heterotrophic iron oxidizer Candidatus Ferristratum. Because this metabolism is inferred from genomes and transcriptomes, the logical next step would be to attempt isolation. However, it is not clear that complete isolation would be successful, as Candidatus Ferristratum sp. appears to require others to remove byproducts to prevent chemodenitrification and toxicity. Instead, we can use our results as a starting point for more specific probing of ecological interactions and metabolite exchange within the mat, which may be unique in iron mats because of the affinity of organics for iron. In addition to affecting local biogeochemistry, organic-bound iron and other metabolites are carried by diffusely venting fluid moving through the mat, exported from Lō'ihi in buoyant plumes for $100 \mathrm{~s}$ to $1000+\mathrm{km}$ [98]. These exported fluids fertilize irondepleted waters, connecting microbial iron and nutrient cycles across ocean basins.

\section{Description of Candidatus Ferristratum gen. nov}

Ferristratum (fer.ri.stra'tum. L. neut. n. ferrum iron; L. neut. n. stratum mat/cover or a layer; N.L. neut. n. Ferristratum from an iron mat layer). Genus defined from nine metagenome-assembled genomes with $>70 \%$ completeness and $<20 \%$ redundancy with an average $77 \%$ pairwise AAI. Genome sources from three unique samples. Type material: MAG S6_Bacteria1 (partial 16S rRNA gene present). Five of the highest-quality ( $>90 \%$ complete, $<5 \%$ redundant) Candidatus Ferristratum sp. genomes have been submitted to IMG under the analysis project IDs Ga0454285Ga0454287, Ga0454293, and Ga0454316 (type material).

Physiological inferences from genome annotation: Heterotrophic. Facultative anaerobic. Capable of respiring nitrate coupled to organic carbon or $\mathrm{Fe}(\mathrm{II})$ oxidation for energy. Capable of nitric oxide reduction and nitrate assimilation. Found within Fe(II)-rich hydrothermal vent bulk/deep mat and sediment environments.

Acknowledgements SMM and CSC conceived of and designed the study, with support from SWP. SMM and CSC conducted sampling. SMM, RV, CSC, and SWP performed analyses. SMM, RV, JLK, and CSC all drafted the manuscript, with edits from SWP. We thank the captain and crew of the R/V Thompson and ROV Jason II. We acknowledge Brian Glazer, Arne Sturm, Angelos Hannides, and Karyn Rogers for their assistance with the shipboard experiment; Jennifer Biddle and Jason Sylvan for input; Julia Maresca for comments on the manuscript; Ryan Moore and Karol Miaskiewicz for bioinformatics assistance; and Jillian Banfield for providing access to ggkbase. This 
work was funded by NSF OCE-1155290 and ONR N00014-17-1-2640 (to CSC); NSF EAR-1833525 (to CSC and SWP); NIGMS P20 GM103446 (to SWP); two Delaware Space Grant Fellowships (NASA grant NNX10AN63H) and the University of Delaware Dissertation Fellowship (to SMM). Computational infrastructure support by the University of Delaware Bioinformatics Core Facility was funded by Delaware INBRE (NIH NIGMS P20 GM103446) and the Delaware Biotechnology Institute.

\section{Compliance with ethical standards}

Conflict of interest The authors declare that they have no conflict of interest.

Publisher's note Springer Nature remains neutral with regard to jurisdictional claims in published maps and institutional affiliations.

Open Access This article is licensed under a Creative Commons Attribution 4.0 International License, which permits use, sharing, adaptation, distribution and reproduction in any medium or format, as long as you give appropriate credit to the original author(s) and the source, provide a link to the Creative Commons license, and indicate if changes were made. The images or other third party material in this article are included in the article's Creative Commons license, unless indicated otherwise in a credit line to the material. If material is not included in the article's Creative Commons license and your intended use is not permitted by statutory regulation or exceeds the permitted use, you will need to obtain permission directly from the copyright holder. To view a copy of this license, visit http://creativecommons. org/licenses/by/4.0/.

\section{References}

1. Karl DM, Wirsen CO, Jannasch HW. Deep-sea primary production at the Galapagos hydrothermal vents. Science (80-). 1980;207:1345-7.

2. Yamamoto M, Takai K. Sulfur metabolisms in epsilon-and gamma-Proteobacteria in deep-sea hydrothermal fields. Front Microbiol. 2011;2:192.

3. Kato S, Nakamura K, Toki T, Ishibashi J-I, Tsunogai U, Hirota A, et al. Iron-based microbial ecosystem on and below the seafloor: a case study of hydrothermal fields of the southern mariana trough. Front Microbiol. 2012;3:89.

4. Winkel M, de Beer D, Lavik G, Peplies J, Mußmann M. Close association of active nitrifiers with Beggiatoa mats covering deepsea hydrothermal sediments. Environ Microbiol. 2014;16:1612-26.

5. Fortunato CS, Larson B, Butterfield DA, Huber JA. Spatially distinct, temporally stable microbial populations mediate biogeochemical cycling at and below the seafloor in hydrothermal vent fluids. Environ Microbiol. 2018;20:769-84.

6. Kendall B, Anbar AD, Kappler A, Konhauser KO. The global iron cycle. In: Knoll AH, Canfield DE, Konhauser KO (eds). Fundamentals of Geobiology, 1st ed. Blackwell Publishing Ltd.; 2012. pp. 65-92.

7. McAllister SM, Moore RM, Gartman A, Luther GW, Emerson D, Chan CS. The Fe(II)-oxidizing Zetaproteobacteria: historical, ecological, and genomic perspectives. FEMS Microbiol Ecol. 2019;95:fiz015.

8. Kato S, Kobayashi C, Kakegawa T, Yamagishi A. Microbial communities in iron-silica-rich microbial mats at deep-sea hydrothermal fields of the Southern Mariana Trough. Environ Microbiol. 2009;11:2094-111.

9. Hassenrück C, Fink A, Lichtschlag A, Tegetmeyer HE, de Beer D, Ramette A. Quantification of the effects of ocean acidification on sediment microbial communities in the environment: The importance of ecosystem approaches. FEMS Microbiol Ecol. 2016;92: fiw02.

10. Kato S, Yanagawa K, Sunamura M, Takano Y, Ishibashi J, Kakegawa $\mathrm{T}$, et al. Abundance of Zetaproteobacteria within crustal fluids in back-arc hydrothermal fields of the Southern Mariana Trough. Environ Microbiol. 2009;11:3210-22.

11. McAllister SM, Davis RE, McBeth JM, Tebo BM, Emerson D, Moyer CL. Biodiversity and emerging biogeography of the neutrophilic iron-oxidizing Zetaproteobacteria. Appl Environ Microbiol. 2011;77:5445-57.

12. Makita H, Kikuchi S, Mitsunobu S, Takaki Y, Yamanaka T, Toki $\mathrm{T}$, et al. Comparative analysis of microbial communities in irondominated flocculent mats in deep-sea hydrothermal environments. Appl Environ Microbiol. 2016;82:5741-55.

13. Scott JJ, Breier JA, Luther GW III, Emerson D. Microbial iron mats at the Mid-Atlantic Ridge and evidence that Zetaproteobacteria may be restricted to iron-oxidizing marine systems. PLoS ONE. 2015;10:e0119284.

14. Scott JJ, Glazer BT, Emerson D. Bringing microbial diversity into focus: high-resolution analysis of iron mats from the Lō'ihi Seamount. Environ Microbiol. 2017;19:301-16.

15. Hager KW, Fullerton H, Butterfield DA, Moyer CL. Community structure of lithotrophically-driven hydrothermal microbial mats from the Mariana Arc and Back-Arc. Front Microbiol. 2017;8:1578

16. Forget NL, Murdock SA, Juniper SK. Bacterial diversity in Ferich hydrothermal sediments at two South Tonga Arc submarine volcanoes. Geobiology. 2010;8:417-32.

17. Vander Roost J, Thorseth IH, Dahle H. Microbial analysis of Zetaproteobacteria and co-colonizers of iron mats in the Troll Wall Vent Field, Arctic Mid-Ocean Ridge. PLoS ONE. 2017;12: e0185008.

18. Rassa AC, McAllister SM, Safran SA, Moyer CL. ZetaProteobacteria dominate the colonization and formation of microbial mats in low-temperature hydrothermal vents at Loihi Seamount, Hawaii. Geomicrobiol J. 2009;26:623-38.

19. Fullerton H, Hager KW, McAllister SM, Moyer CL. Hidden diversity revealed by genome-resolved metagenomics of ironoxidizing microbial mats from Lo'ihi Seamount, Hawai'i. ISME J. 2017;11:1900-14.

20. Field EK, Sczyrba A, Lyman AE, Harris CC, Woyke T, Stepanauskas R, et al. Genomic insights into the uncultivated marine Zetaproteobacteria at Loihi Seamount. ISME J. 2015;9:857-70.

21. Chan CS, McAllister SM, Leavitt AH, Glazer BT, Krepski ST, Emerson D. The architecture of iron microbial mats reflects the adaptation of chemolithotrophic iron oxidation in freshwater and marine environments. Front Microbiol. 2016;7:796.

22. Fleming EJ, Davis RE, McAllister SM, Chan CS, Moyer CL, Tebo BM, et al. Hidden in plain sight: discovery of sheathforming, iron-oxidizing Zetaproteobacteria at Loihi Seamount, Hawaii, USA. FEMS Microbiol Ecol. 2013;85:116-27.

23. Barco RA, Emerson D, Sylvan JB, Orcutt BN, Jacobson Meyers ME, Ramírez GA, et al. New insight into microbial iron oxidation as revealed by the proteomic profile of an obligate iron-oxidizing chemolithoautotroph. Appl Environ Microbiol. 2015;81:5927-37.

24. McAllister SM, Polson SW, Butterfield DA, Glazer BT, Sylvan $\mathrm{JB}$, Chan CS. Validating the Cyc2 neutrophilic iron oxidation pathway using meta-omics of Zetaproteobacteria iron mats at marine hydrothermal vents. mSystems. 2020;5:e00553-19.

25. Singer E, Emerson D, Webb EA, Barco RA, Kuenen JG, Nelson WC, et al. Mariprofundus ferrooxydans, PV-1 the first genome of a marine $\mathrm{Fe}$ (II) oxidizing Zetaproteobacterium. PLoS ONE. 2011;6:e25386.

26. Mori JF, Scott JJ, Hager KW, Moyer CL, Küsel K, Emerson D. Physiological and ecological implications of an iron- or hydrogen- 
oxidizing member of the Zetaproteobacteria, Ghiorsea bivora, gen. nov., sp. nov. ISME J. 2017;11:2624-36.

27. Zimmerman AE, Howard-Varona C, Needham DM, John SG, Worden AZ, Sullivan MB, et al. Metabolic and biogeochemical consequences of viral infection in aquatic ecosystems. Nat Rev Microbiol. 2020;18:21-34.

28. Bennett SA, Hansman RL, Sessions AL, Nakamura K, Edwards KJ. Tracing iron-fueled microbial carbon production within the hydrothermal plume at the Loihi seamount. Geochim Cosmochim Acta. 2011;75:5526-39.

29. Jesser KJ, Fullerton H, Hager KW, Moyer CL. Quantitative PCR analysis of functional genes in iron-rich microbial mats at an active hydrothermal vent system (Lō'ihi Seamount, Hawai'i). Appl Environ Microbiol. 2015;81:2976-84.

30. Singer E, Heidelberg JF, Dhillon A, Edwards KJ. Metagenomic insights into the dominant $\mathrm{Fe}$ (II) oxidizing Zetaproteobacteria from an iron mat at Lō'ihi, Hawai'i. Front Microbiol. 2013;4:52.

31. Chiu BK, Kato S, McAllister SM, Field EK, Chan CS. Novel pelagic iron-oxidizing Zetaproteobacteria from the Chesapeake Bay oxic-anoxic transition zone. Front Microbiol. 2017;8:1280.

32. Makita H, Tanaka E, Mitsunobu S, Miyazaki M, Nunoura T, Uematsu K, et al. Mariprofundus micogutta sp. nov., a novel ironoxidizing zetaproteobacterium isolated from a deep-sea hydrothermal field at the Bayonnaise knoll of the Izu-Ogasawara arc, and a description of Mariprofundales ord. nov. and Zetaproteobacteria classis. Arch Microbiol. 2017;199:335-46.

33. Laufer K, Nordhoff M, Halama M, Martinez RE, Obst M, Nowak $\mathrm{M}$, et al. Microaerophilic $\mathrm{Fe}(\mathrm{II})$-oxidizing Zetaproteobacteria isolated from low-Fe marine coastal sediments: Physiology and characterization of their twisted stalks. Appl Environ Microbiol. 2017;83:e03118-16.

34. Glazer BT, Rouxel OJ. Redox speciation and distribution within diverse iron-dominated microbial habitats at Loihi Seamount. Geomicrobiol J. 2009;26:606-22.

35. Sylvan JB, Wankel SD, LaRowe DE, Charoenpong CN, Huber JA, Moyer CL, et al. Evidence for microbial mediation of subseafloor nitrogen redox processes at Loihi Seamount, Hawaii. Geochim Cosmochim Acta. 2017;198:131-50.

36. Sedwick PN, McMurtry GM, Macdougall JD. Chemistry of hydrothermal solutions from Pele's Vents, Loihi Seamount, Hawaii. Geochim Cosmochim Acta. 1992;56:3643-67.

37. Karl DM, Brittain AM, Tilbrook BD. Hydrothermal and microbial processes at Loihi Seamount, a mid-plate hot-spot volcano. Deep Sea Res Part A, Oceanogr Res Pap. 1989;36:1655-73.

38. Bryce C, Blackwell N, Schmidt C, Otte J, Huang YM, Kleindienst $\mathrm{S}$, et al. Microbial anaerobic $\mathrm{Fe}(\mathrm{II})$ oxidation-ecology, mechanisms and environmental implications. Environ Microbiol. 2018;20:3462-83.

39. Laufer K, Byrne JM, Glombitza C, Schmidt C, Jørgensen BB, Kappler A. Anaerobic microbial Fe(II) oxidation and Fe(III) reduction in coastal marine sediments controlled by organic carbon content. Environ Microbiol. 2016;18:3159-74.

40. Robertson EK, Roberts KL, Burdorf LDW, Cook P, Thamdrup B. Dissimilatory nitrate reduction to ammonium coupled to $\mathrm{Fe}$ (II) oxidation in sediments of a periodically hypoxic estuary. Limnol Oceanogr. 2016;61:365-81.

41. Glöckner FO, Yilmaz P, Quast C, Gerken J, Beccati A, Ciuprina A, et al. 25 years of serving the community with ribosomal RNA gene reference databases and tools. J Biotechnol. 2017;261:169-76.

42. Nurk S, Meleshko D, Korobeynikov A, Pevzner PA. metaSPAdes: a new versatile metagenomic assembler. Genome Res. 2017;27:824-34.

43. Sieber CMK, Probst AJ, Sharrar A, Thomas BC, Hess M, Tringe $\mathrm{SG}$, et al. Recovery of genomes from metagenomes via a dereplication, aggregation and scoring strategy. Nat Microbiol. 2018;3:836-43.

44. Wu Y-W, Tang Y-H, Tringe SG, Simmons BA, Singer SW. MaxBin: an automated binning method to recover individual genomes from metagenomes using an expectation-maximization algorithm. Microbiome. 2014;2:26.

45. Kang DD, Froula J, Egan R, Wang Z. MetaBAT, an efficient tool for accurately reconstructing single genomes from complex microbial communities. PeerJ. 2015;3:e1165.

46. Alneberg J, Bjarnason BS, De Bruijn I, Schirmer M, Quick J, Ijaz $\mathrm{UZ}$, et al. Binning metagenomic contigs by coverage and composition. Nat Methods. 2014;11:1144-6.

47. Graham ED, Heidelberg JF, Tully BJ. BinSanity: unsupervised clustering of environmental microbial assemblies using coverage and affinity propagation. PeerJ. 2017;5:e3035.

48. Eren AM, Esen ÖC, Quince C, Vineis JH, Morrison HG, Sogin ML, et al. Anvi'o: an advanced analysis and visualization platform for 'omics data. PeerJ. 2015;3:e1319.

49. Quinlan AR, Hall IM. BEDTools: A flexible suite of utilities for comparing genomic features. Bioinformatics. 2010;26:841-2.

50. Wagner GP, Kin K, Lynch VJ. Measurement of mRNA abundance using RNA-seq data: RPKM measure is inconsistent among samples. Theory Biosci. 2012;131:281-5.

51. Anders S, Huber W. Differential expression analysis for sequence count data. Genome Biol. 2010;11:R106.

52. Overbeek R, Olson R, Pusch GD, Olsen GJ, Davis JJ, Disz T, et al. The SEED and the rapid annotation of microbial genomes using subsystems technology (RAST). Nucleic Acids Res. 2014;42:D206-14.

53. Kanehisa M, Sato Y, Morishima K. BlastKOALA and GhostKOALA: KEGG Tools for functional characterization of genome and metagenome sequences. J Mol Biol. 2016;428:726-31.

54. Anantharaman K, Brown CT, Hug LA, Sharon I, Castelle CJ, Probst AJ, et al. Thousands of microbial genomes shed light on interconnected biogeochemical processes in an aquifer system. Nat Commun. 2016;7:13219.

55. Garber AI, Nealson KH, Okamoto A, McAllister SM, Chan CS, Barco RA, et al. FeGenie: a comprehensive tool for the identification of iron genes and iron gene neighborhoods in genome and metagenome assemblies. Front Microbiol. 2020;11:37.

56. Camacho C, Coulouris G, Avagyan V, Ma N, Papadopoulos J, Bealer K, et al. BLAST+: architecture and applications. BMC Bioinforma. 2009;10:421.

57. Parks DH, Chuvochina M, Waite DW, Rinke C, Skarshewski A, Chaumeil P-A, et al. A standardized bacterial taxonomy based on genome phylogeny substantially revises the tree of life. Nat Biotechnol. 2018;36:996-1004.

58. Quast C, Pruesse E, Yilmaz P, Gerken J, Schweer T, Yarza P, et al. The SILVA ribosomal RNA gene database project: Improved data processing and web-based tools. Nucleic Acids Res. 2013;41:D590-6.

59. Pruesse E, Peplies J, Glöckner FO. SINA: Accurate highthroughput multiple sequence alignment of ribosomal RNA genes. Bioinformatics. 2012;28:1823-9.

60. Stamatakis A, Hoover P, Rougemont J. A rapid bootstrap algorithm for the RAxML web servers. Syst Biol. 2008;57:758-71.

61. Moore RM, Harrison AO, McAllister SM, Polson SW, Wommack KE. Iroki: automatic customization and visualization of phylogenetic trees. PeerJ. 2020;8:e8584.

62. Darling AE, Jospin G, Lowe E, Matsen FA, Bik HM, Eisen JA. PhyloSift: phylogenetic analysis of genomes and metagenomes. PeerJ. 2014;2:e243.

63. Parks DH, Imelfort M, Skennerton CT, Hugenholtz P, Tyson GW. CheckM: assessing the quality of microbial genomes recovered from. Genome Res. 2015;25:1043-55. 
64. Roux S, Enault F, Hurwitz BL, Sullivan MB. VirSorter: mining viral signal from microbial genomic data. PeerJ. 2015;3:e985.

65. Wommack KE, Bhavsar J, Polson SW, Chen J, Dumas M, Srinivasiah S, et al. VIROME: a standard operating procedure for analysis of viral metagenome sequences. Stand Genom Sci. 2012;6:421-33.

66. Bolduc B, Jang HBin, Doulcier G, You Z-Q, Roux S, Sullivan MB. vConTACT: an iVirus tool to classify double-stranded DNA viruses that infect Archaea and Bacteria. PeerJ. 2017;5:e3243.

67. Gregory AC, Zayed AA, Conceição-Neto N, Temperton B, Bolduc B, Alberti A, et al. Marine DNA viral macro- and microdiversity from pole to pole. Cell. 2019;177:1109-23.

68. Nasko DJ, Ferrell BD, Moore RM, Bhavsar JD, Polson SW, Wommack KE. CRISPR spacers indicate preferential matching of specific virioplankton genes. MBio. 2019;10:e02651-18.

69. Lau MCY, Aitchison JC, Pointing SB. Bacterial community composition in thermophilic microbial mats from five hot springs in central Tibet. Extremophiles. 2009;13:139-49.

70. Qiu Y, Hanada S, Ohashi A, Harada H, Kamagata Y, Sekiguchi Y. Syntrophorhabdus aromaticivorans gen. nov., sp. nov., the first cultured anaerobe capable of degrading phenol to acetate in obligate syntrophic associations with a hydrogenotrophic methanogen. Appl Environ Microbiol. 2008;74:2051-8.

71. Nobu MK, Narihiro T, Tamaki H, Qiu Y, Sekiguchi Y, Woyke T, et al. The genome of Syntrophorhabdus aromaticivorans strain UI provides new insights for syntrophic aromatic compound metabolism and electron flow. Environ Microbiol. 2015;17:4861-72.

72. Omoregie EO, Mastalerz V, de Lange G, Straub KL, Kappler A, $\mathrm{R} \varnothing \mathrm{y} \mathrm{H}$, et al. Biogeochemistry and community composition of iron- and sulfur-precipitating microbial mats at the Chefren mud volcano (Nile deep sea fan, eastern Mediterranean). Appl Environ Microbiol. 2008;74:3198-215.

73. Konstantinidis KT, Rosselló-Móra R, Amann R. Uncultivated microbes in need of their own taxonomy. ISME J. 2017;11:2399-406

74. Williamson SJ, Cary SC, Williamson KE, Helton RR, Bench SR, Winget $\mathrm{D}$, et al. Lysogenic virus-host interactions predominate at deep-sea diffuse-flow hydrothermal vents. ISME J. 2008;2:1112-21.

75. Sharma A, Schmidt M, Kiesel B, Mahato NK, Cralle L, Singh Y, et al. Bacterial and Archaeal viruses of Himalayan hot springs at Manikaran modulate host genomes. Front Microbiol. 2018;9:3095.

76. Anderson RE, Sogin ML, Baross JA. Evolutionary strategies of viruses, bacteria and archaea in hydrothermal vent ecosystems revealed through metagenomics. PLoS ONE. 2014;9:e109696.

77. Emerson D, Moyer CL. Neutrophilic Fe-oxidizing bacteria are abundant at the Loihi Seamount hydrothermal vents and play a major role in $\mathrm{Fe}$ oxide deposition. Appl Environ Microbiol. 2002;68:3085-93.

78. Emerson D, Fleming EJ, McBeth JM. Iron-oxidizing bacteria: an environmental and genomic perspective. Annu Rev Microbiol. 2010;64:561-83.

79. Hernsdorf AW, Amano Y, Miyakawa K, Ise K, Suzuki Y, Anantharaman K, et al. Potential for microbial $\mathrm{H} 2$ and metal transformations associated with novel bacteria and archaea in deep terrestrial subsurface sediments. ISME J. 2017;11:1915-29.

80. Quaiser A, Bodi X, Dufresne A, Naquin D, Francez A-J, Dheilly A, et al. Unraveling the stratification of an iron-oxidizing microbial mat by metatranscriptomics. PLoS ONE. 2014;9:e102561.
81. Kato S, Chan C, Itoh T, Ohkuma M. Functional gene analysis of freshwater iron-rich flocs at circumneutral $\mathrm{ph}$ and isolation of a stalk-forming microaerophilic iron-oxidizing bacterium. Appl Environ Microbiol. 2013;79:5283-90.

82. Hemp J, Gennis RB. Diversity of the heme-copper superfamily in Archaea: Insights from genomics and structural modeling. Results Probl Cell Differ. 2008;45:1-31.

83. Ferris FG. Biogeochemical properties of bacteriogenic iron oxides. Geomicrobiol J. 2005;22:79-85.

84. Sowers TD, Harrington JM, Polizzotto ML, Duckworth OW. Sorption of arsenic to biogenic iron (oxyhydr)oxides produced in circumneutral environments. Geochim Cosmochim Acta. 2017;198:194-207.

85. Bennett SA, Toner BM, Barco R, Edwards KJ. Carbon adsorption onto $\mathrm{Fe}$ oxyhydroxide stalks produced by a lithotrophic ironoxidizing bacteria. Geobiology. 2014;12:146-56.

86. Rentz JA, Turner IP, Ullman JL. Removal of phosphorus from solution using biogenic iron oxides. Water Res. 2009;43:2029-35.

87. Chan CS, Fakra SC, Emerson D, Fleming EJ, Edwards KJ. Lithotrophic iron-oxidizing bacteria produce organic stalks to control mineral growth: implications for biosignature formation. ISME J. 2011;5:717-27.

88. Bennett SA, Toner BM, Barco R, Edwards KJ. Carbon adsorption onto $\mathrm{Fe}$ oxyhydroxide stalks produced by a lithotrophic ironoxidizing bacteria. Geobiology. 2014;12:146-56.

89. Wilhelm SW, Suttle CA. Viruses and nutrient cycles in the sea: Viruses play critical roles in the structure and function of aquatic food webs. Bioscience. 1999;49:781-8.

90. Chen J, Strous M. Denitrification and aerobic respiration, hybrid electron transport chains and co-evolution. Biochim Biophys Acta. 2013;1827:136-44.

91. Choi PS, Naal Z, Moore C, Casado-Rivera E, Abruña HD, Helmann JD, et al. Assessing the impact of denitrifier-produced nitric oxide on other bacteria. Appl Environ Microbiol. 2006;72:2200-5.

92. Klueglein N, Kappler A. Abiotic oxidation of Fe(II) by reactive nitrogen species in cultures of the nitrate-reducing $\mathrm{Fe}(\mathrm{II})$ oxidizer Acidovorax sp. BoFeN1 - questioning the existence of enzymatic Fe(II) oxidation. Geobiology. 2013;11:180-90.

93. Hafenbradl D, Keller M, Dirmeier R, Rachel R, Roßnagel P, Burggraf $\mathrm{S}$, et al. Ferroglobus placidus gen. nov., sp. nov., a novel hyperthermophilic archaeum that oxidizes $\mathrm{Fe} 2+$ at neutral $\mathrm{pH}$ under anoxic conditions. Arch Microbiol. 1996;166:308-14.

94. He S, Tominski C, Kappler A, Behrens S, Roden EE. Metagenomic analyses of the autotrophic $\mathrm{Fe}$ (II)-oxidizing, nitratereducing enrichment culture KS. Appl Environ Microbiol. 2016;82:2656-68

95. Straub KL, Benz M, Schink B, Widdel F. Anaerobic, nitratedependent microbial oxidation of ferrous iron. Appl Environ Microbiol. 1996;62:1458-60.

96. Blöthe M, Roden EE. Composition and activity of an autotrophic $\mathrm{Fe}(\mathrm{II})$-oxidizing, nitrate-reducing enrichment culture. Appl Environ Microbiol. 2009;75:6937-40.

97. Emerson D, Scott JJ, Leavitt A, Fleming E, Moyer C. In situ estimates of iron-oxidation and accretion rates for iron-oxidizing bacterial mats at Lō'ihi Seamount. Deep Res Part I Oceanogr Res Pap. 2017;126:31-9.

98. Jenkins WJ, Hatta M, Fitzsimmons JN, Schlitzer R, Lanning NT, Shiller A, et al. An intermediate-depth source of hydrothermal $3 \mathrm{He}$ and dissolved iron in the North Pacific. Earth Planet Sci Lett. 2020;539:116223. 